\title{
Determining optimal pinger spacing for harbour porpoise bycatch mitigation
}

\author{
Finn Larsen ${ }^{1, *}$, Carsten $\operatorname{Krog}^{2}$, Ole Ritzau Eigaard ${ }^{1}$ \\ ${ }^{1}$ National Institute of Aquatic Resources, Technical University of Denmark, 2920 Charlottenlund, Denmark \\ ${ }^{2}$ Krog Consult ApS, 6700 Esbjerg, Denmark
}

\begin{abstract}
A trial was conducted in the Danish North Sea hake gillnet fishery in July to September 2006 to determine whether the spacing of the Aquatec AQUAmark100 pinger could be increased without reducing the effectiveness of the pinger in mitigating harbour porpoise bycatch. The trial was designed as a controlled experiment where nets without pingers formed the control group (41 hauls) and nets with pingers spaced at $455 \mathrm{~m}$ (24 hauls) and $585 \mathrm{~m}$ (43 hauls), respectively, formed the 2 experimental groups. Nets without pingers had a bycatch frequency of 0.54 incidents per haul, nets with pingers spaced at $585 \mathrm{~m}$ had a bycatch frequency of 0.12 incidents per haul, and nets with pingers spaced at $455 \mathrm{~m}$ had a bycatch frequency of 0 . The bycatch frequencies for the 2 experimental groups were both significantly different from the bycatch frequencies of the control group $(\mathrm{p}<0.0001)$. These results show that the spacing of the Aquatec AQUAmark100 pinger can be increased without reducing the effectiveness of the pinger in mitigating harbour porpoise bycatch, thereby reducing some of the disadvantages of widespread pinger deployment. The results also stress the importance of basing implementation regulation on solid evidence and led the Danish Fisheries Directorate in 2007 to allow the use of the AQUAmark100 pinger with a spacing of up to $455 \mathrm{~m}$ under derogation to the European Union's Council Regulation No. 812/2004.
\end{abstract}

KEY WORDS: Phocoena phocoena $\cdot$ Bycatch mitigation · Pinger spacing $\cdot$ Experimental fishery

Resale or republication not permitted without written consent of the publisher

\section{INTRODUCTION}

Bycatch in commercial fisheries is probably the most important single threat to many populations of small cetaceans worldwide (Perrin et al. 1994, Read et al. 2006, Read 2008) and has led to the introduction of various management measures. These management measures include, among others, the mandatory use of acoustic deterrents (so-called pingers) in certain fisheries, e.g. the Gulf of Maine sink gillnet fishery, the California driftnet fishery for swordfish and sharks and certain gillnet fisheries in European waters.

Pingers have proven to be very effective at reducing bycatch of small cetaceans in gillnets, particu- larly of harbour porpoises Phocoena phocoena (Kraus et al. 1997, Larsen 1997, Gearin et al. 1999, Trippel et al. 1999, Gönener \& Bilgin 2009), but they also have some disadvantages, which are limiting their acceptance by managers, fishermen and environmentalists. These disadvantages may include high costs, interference with fishing operations, introduction of noise into the marine environment, habituation resulting in reduced effectiveness, exclusion of porpoises from important habitats and alerting seals to the nets to depredate on the catch.

In Europe, mandatory use of pingers deployed to reduce bycatch of harbour porpoises is regulated through the European Union's Council Regulation No. 812/2004 (CR812, http://eur-lex.europa.eu/). 
Annex II of CR812 includes the technical specifications and conditions for use of pingers. With respect to pinger spacing, i.e. the maximum spacing between 2 pingers along nets, the council regulation follows the advice of the pinger manufacturers, giving 200 and $100 \mathrm{~m}$, respectively, for the 2 different types of pingers defined in Annex II of CR812.

Experiments conducted with porpoises in the wild suggest, however, that pingers may be effective at considerably longer ranges than $200 \mathrm{~m}$ (Goodson et al. 1997, Culik et al. 2001, Carlström et al. 2009). If that is indeed the case, pingers could be deployed with larger spacing than allowed by CR812 and still remain effective, while a number of the disadvantages mentioned above would be reduced.

In 2006, the potential advantages of a more optimal pinger spacing led the Danish Institute for Fisheries Research (DIFRES) in collaboration with the Danish Fishermen's Association, represented by Krog Consult ApS, to conduct a trial with pingers spaced at different intervals along the nets. The aim of the trial was to establish whether pingers could be deployed with larger spacing than specified in CR812 without reducing the effectiveness of the pingers in mitigating bycatch of harbour porpoises. The present paper presents and discusses the results of the trial.

\section{MATERIALS AND METHODS}

The most reliable way to determine the effective range of a particular pinger is to conduct a number of experiments with different pinger spacings in a commercial fishery to parameterize a statistical model giving the relationship between pinger spacing and pinger effectiveness. However, this is a very expensive procedure. An alternative and less expensive approach is to conduct controlled experiments with just 1 or 2 spacings, which are chosen based on results from other types of pinger experiments, as was done in the present trial.

\section{Trial design, fishery and gear}

The trial was designed as a controlled experiment, where the control group consisted of nets without pingers and the 2 experimental groups consisted of nets with pingers spaced at 2 different intervals. Each of the experimental groups was always fished concurrently with a control group within trips, and mostly also concurrent with each other, and all trips included in the following data analysis had 100\% observer coverage.

The trial was conducted in the Danish North Sea hake gillnet fishery, which is pursued in July to September by a small number of fishing vessels from harbours in western Jutland. The nets used in this fishery are made from $0.57 \mathrm{~mm}$ mono twine; stretched mesh size is 120 or $130 \mathrm{~mm}$, and height is 40.5 meshes (corresponding to ca. $3 \mathrm{~m}$ ). The length of each individual net is 2000 knots (1000 stretched meshes), which are attached to a head rope of $65 \mathrm{~m}$ giving a hanging ratio of ca. 0.5. The nets were tied together and stored on board in strings of 9 nets, and the strings were tied together during setting to form fleets of nets ranging in size from 45 to 135 nets. Most fleets were set east-west, but a few were set along bottom contours.

\section{Pingers and spacing}

Based on preliminary results from an ongoing large-scale trial of pingers in Danish gillnet fisheries (Krog \& Larsen 2007), we decided to use the Aquatec AQUAmark100 pinger for the spacing trial. Technical specifications for this pinger can be found on the Aquatec website (www.netpinger.net). Source level for the AQUAmark100 was determined to be 136 to $145 \mathrm{~dB}$ re. $1 \mu \mathrm{Pa} @ 1 \mathrm{~m}$. According to CR812, Annex II, the maximum spacing for a pinger with these specifications is $200 \mathrm{~m}$. During the trial, pingers in the 2 experimental groups were spaced at 455 and $585 \mathrm{~m}$, respectively. These spacings allowed pingers to be attached to the bridles between nets, resulting in fewer handling problems than attachment on the headrope. To avoid fleets affecting each other, the distances between individual fleets were required to be at least the same as the pinger spacing.

\section{Data collection and analyses}

The trial was fully covered by on-board observers, whose main functions were to record data on bycatch of harbour porpoises and carry out regular checks of the pingers to ensure that they were functioning correctly. Data were collected on a haul basis, where a haul was 1 or more fleets of nets set at approximately the same time and position, either without pingers or with pingers attached with the required spacing, and hauled together. Data col- 
lected for each haul included time and position for setting and hauling the nets, number of nets set, number of pingers deployed and number of porpoises and hake caught.

The sampling unit was a haul, and the bycatch was assumed to follow a binomial distribution. Each haul was given the value 1 if there was bycatch of 1 or more porpoises, and 0 if there was no bycatch. This choice of sampling unit and underlying bycatch distribution was necessary because it cannot be assumed that the individual nets of a haul are fishing independently of each other. The frequency of porpoise bycatch incidents for each experimental group was thus the number of hauls with bycatch divided by the total number of hauls in the group. A $\chi^{2}$-test (Fisher's exact test, 2-sided) was used to determine whether the bycatch frequencies of the 3 groups of hauls were significantly different from each other (Sokal \& Rohlf 1995). To allow comparison with other experiments and observations of marine mammal bycatch rates in gill nets, total bycatch of porpoises per $\mathrm{km}$ of netting and soaking time in days $\left(\mathrm{km}^{-1} \mathrm{~d}^{-1}\right)$ was also calculated for experimental and control groups.

Catch rates for hake were calculated as the mean number of fish caught per $\mathrm{km}$ of netting and days of soaking time $\left(\mathrm{km}^{-1} \mathrm{~d}^{-1}\right)$ for hauls with pingers and hauls without pingers, and a Student's $t$-test (unequal variance) was used to determine whether catch rates were significantly different (Sokal \& Rohlf 1995).

Unfortunately, the observers failed to abide fully to the experimental protocol throughout the experiment, and hake catches were only recorded for 27 hauls (12 without pingers, 14 with a pinger spacing of $455 \mathrm{~m}$ and 1 with a pinger spacing of $585 \mathrm{~m}$ ). Consequently, only the mean catch rates for control nets and nets with $455 \mathrm{~m}$ spacing could be calculated and tested statistically for differences.

\section{RESULTS}

The trial was conducted on board a commercial gillnet vessel in the Danish North Sea hake fishery during 9 wk in July to September 2006. Problems with availability of the observers meant that in this period the observers covered only 5 fishing trips for a total of $21 \mathrm{~d}$ of fishing; these form the basis of our analyses. Data were recorded from a total of 112 hauls, but 4 of these were discarded from further analyses because they did not conform to the requirements of the experimental design in that the fleets were too close to each other. For the remain- ing 108 hauls, the experimental nets of either 455 or $585 \mathrm{~m}$ pinger distance were always fished concurrently with a control group within trips, and for 3 out of 5 trips also concurrent with each other (Table 1, Fig. 1). The numbers of nets fished did not differ among the 3 haul types (Fig. 2).

A total of 50 porpoises were caught during the trial, of which 45 were caught in nets without pingers (corresponding to a bycatch rate of 0.51 porpoises $\mathrm{km}^{-1}$ $\left.\mathrm{d}^{-1}\right), 5$ were caught in nets where the pinger spacing was $585 \mathrm{~m}$ (corresponding to 0.05 porpoises $\mathrm{km}^{-1}$ $\mathrm{d}^{-1}$ ), and no porpoises were caught in nets where the pinger spacing was $455 \mathrm{~m}$ (Table 1). The frequency of bycatch incidents was 0.54 (22 of 41 hauls) for the control group without pingers, 0.12 (5 of 43 hauls) for the group with a pinger spacing of $585 \mathrm{~m}$ and 0 ( 0 of 24 hauls) for the group with a pinger spacing of $455 \mathrm{~m}$. The frequencies of bycatch incidents for both experimental groups were significantly different from the bycatch rate for the control group hauls $(\mathrm{p}<$ $0.0001 ; 1 \mathrm{df})$. The bycatch frequencies of the 2 experimental groups were not significantly different $(\mathrm{p}=$ $0.10 ; 1 \mathrm{df})$.

In this trial, the effect of using pingers with a spacing of $455 \mathrm{~m}$ was a $100 \%$ reduction of bycatch, whereas the effect of using pingers with a spacing of $585 \mathrm{~m}$ was a $78 \%$ reduction of bycatch.

In control nets, the mean $\pm \mathrm{SD}$ catch rate for hake was $29.0 \pm 10.2$ fish $\mathrm{km}^{-1} \mathrm{~d}^{-1}$ and in nets with pinger spacings of $455 \mathrm{~m}$ it was $30.4 \pm 13.3$ fish $\mathrm{km}^{-1} \mathrm{~d}^{-1}$. This small difference was not significant in a Student's $t$-test $(\mathrm{p}=0.76 ; 24 \mathrm{df})$.

\section{DISCUSSION}

The manufacturers of pingers argue for their recommended pinger spacing in 1 of 2 ways. Some manufacturers refer to experiments conducted with specific pingers in a commercial fishery and recommend

Table 1. Number of hauls and porpoise Phocoena phocoena bycatches (in parentheses) by trip and haul type. Dates are shown as dd/mm

\begin{tabular}{|lcccc|}
\hline Trip & Date & $\begin{array}{c}\text { Control } \\
\text { hauls }\end{array}$ & $\begin{array}{c}455 \mathrm{~m} \\
\text { hauls }\end{array}$ & $\begin{array}{c}585 \mathrm{~m} \\
\text { hauls }\end{array}$ \\
\hline 1 & $16 / 7-18 / 7$ & $12(14)$ & $9(0)$ & $1(0)$ \\
2 & $23 / 7-25 / 7$ & $8(5)$ & $7(0)$ & $7(1)$ \\
3 & $30 / 7-01 / 8$ & $10(22)$ & $8(0)$ & $6(1)$ \\
4 & $13 / 8-16 / 8$ & $7(2)$ & & $15(2)$ \\
5 & $10 / 9-13 / 9$ & $4(2)$ & & $14(1)$ \\
Total & & $41(45)$ & $24(0)$ & $43(5)$ \\
\hline
\end{tabular}




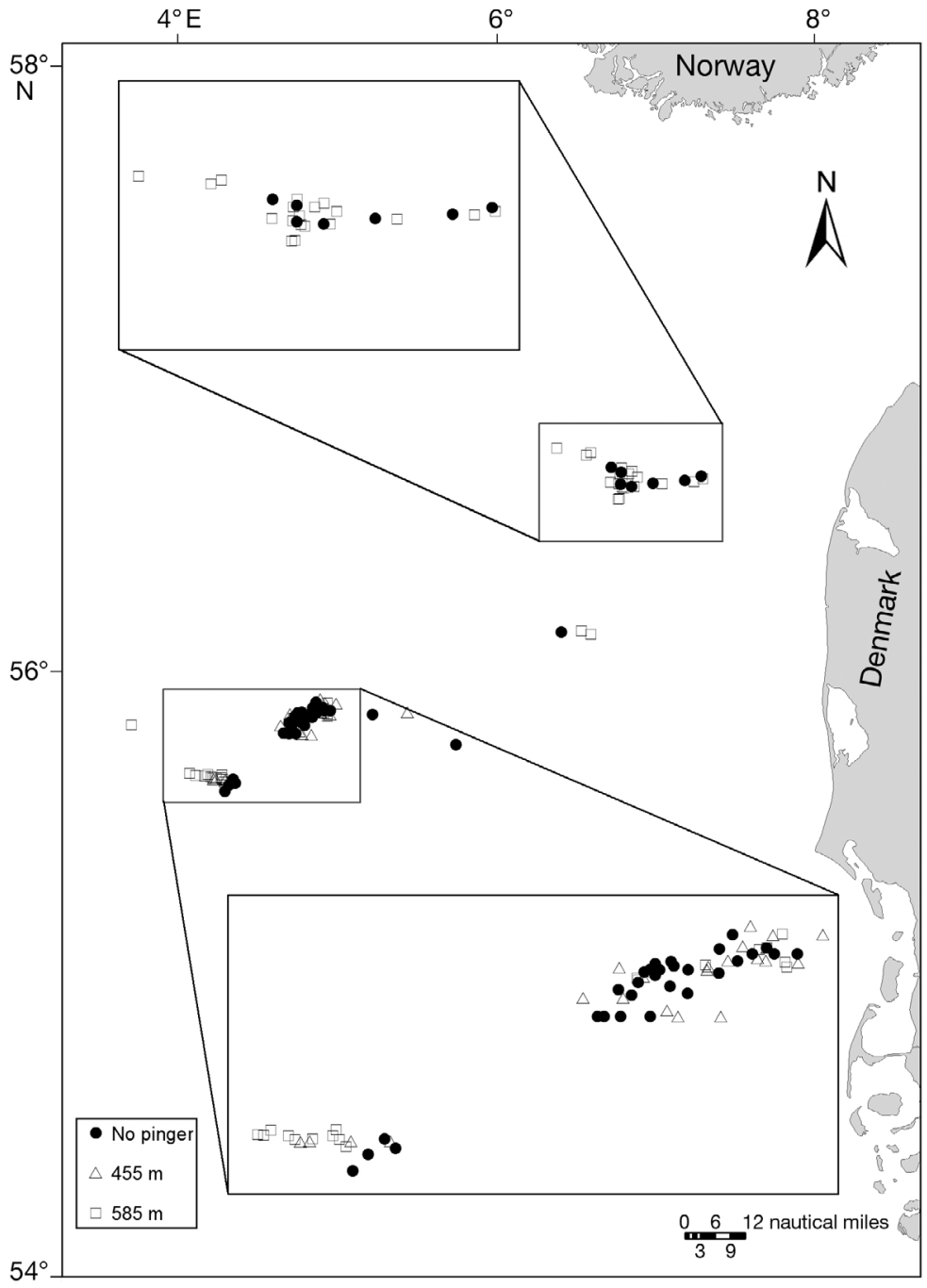

Fig. 1. Geographical distribution of hauls with and without pingers for all 5 fishing trips included in the experiment showing distances between hauls (455 and $585 \mathrm{~m}$ )

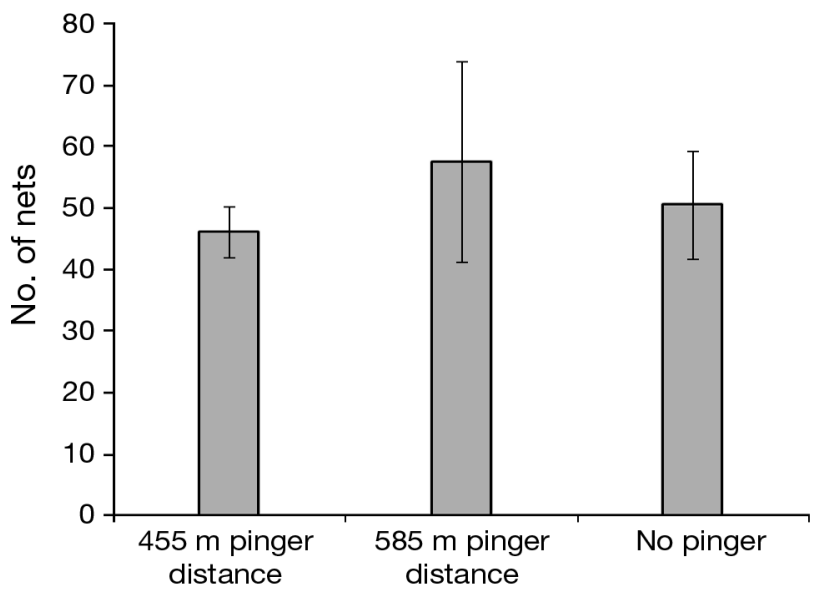

Fig. 2. Average number of nets per haul. Error bars represent SD that the spacing used in the experiments should not be increased. However, since none of these experiments were aimed at determining the effective range of the pingers, the results of these experiments are not very informative about the optimal pinger spacing.

Other manufacturers claim that to be effective, pinger signals have to be a certain level above the background noise level. Although this may be a more valid approach, no experiments have been conducted to determine how much above the background noise level pinger signals have to be in order to be effective.

A third option is to conduct studies of porpoise behaviour around pingers in the wild, specifically studying the distribution of porpoises as a function of distance to the pinger. Several such studies have been conducted in recent years (Cox et al. 2001, Culik et al. 2001), but it is not obvious, if at all possible, how to translate such distributions into an effective range of the pinger in question. This is exacerbated by the lack of an agreed definition of what the term 'effective range' actually means.

The manufacturer of the pinger used in the trial presented in this paper uses the first argument, and refers to the results from a large-scale pinger trial, conducted by DIFRES in 1997 (Larsen 1997), where pingers were deployed with a spacing of $140 \mathrm{~m}$. However, the 1997 DIFRES trial was aimed at determining whether the concept of using pingers to reduce porpoise bycatch was viable and was not concerned about optimising pinger spacing. Because of this, and because the trial was conducted with a prototype pinger whose reliability was unknown, pingers were deliberately spaced with a considerable overlap, based on the expected effective range of this pinger. Therefore, the results from the DIFRES 1997 trial cannot be used to determine the maximum pinger spacing.

A small-scale experiment conducted in Scotland in 1997 with wild, naïve porpoises exposed to a similar prototype pinger as in the DIFRES 1997 trial, but with a higher source level, suggested that this pinger had an effect at a distance of ca. $600 \mathrm{~m}$ (Goodson et al. 1997). This corresponds to ca. $400 \mathrm{~m}$ if the source level is adjusted to that of the pinger used in the DIFRES 1997 trial. 
The results of the present trial support the argument that pingers are effective at longer ranges than the manufacturers' recommended spacings would suggest. When pingers were spaced $455 \mathrm{~m}$ apart, the harbour porpoise bycatch was reduced to 0 , and even when spaced $585 \mathrm{~m}$ apart the bycatch was reduced to $22 \%$ of that in the control group of nets. These reductions are similar in magnitude to reductions reported in other pinger trials, where pingers were deployed with considerably smaller spacing (Table 2). It should be noted, however, that the 2 effect sizes (100 and $78 \%$, respectively) are not significantly different.

The results presented in this report suggest that in the Danish hake gillnet fishery, the maximum spacing of AQUAmark100 pingers can be increased to at least $455 \mathrm{~m}$ without reducing their effectiveness. This probably also applies to the Danish gillnet fisheries in general. Of the various factors which could conceivably influence the effective range of the pingers, apparently only the pinger height above the seabed is different between the hake gillnet fishery and other gillnet fisheries. In the Danish gillnet fishery, the fishing height of hake nets is ca. $3 \mathrm{~m}$, that of cod nets is ca. $2 \mathrm{~m}$, that of turbot nets ca. $1.5 \mathrm{~m}$, and that of plaice gillnets ca. $1 \mathrm{~m}$ (Hvalpsund Net A/S: www. onsitecatalog.com/catalogs/1552/3948/\#/0), but it does not seem plausible that these differences should have a large effect on the effective range of the pinger, if the pingers are deployed correctly, e.g. with sufficient floatation to counter the negative buoyancy of the AQUAmark100 pinger. We therefore suggest that the AQUAmark100 pinger would be equally efficient in other Danish gillnet fisheries as in the hake fishery and could be used with a spacing well above the $200 \mathrm{~m}$ recommended by the manufacturer. This led the Danish Fisheries Directorate in 2007 to allow the use of the AQUAmark100 pinger with a spacing of up to $455 \mathrm{~m}$ under derogation to CR812, and this was followed later with a similar Irish derogation.

Nevertheless, since the circumstances leading to bycatch of harbour porpoises in gillnets are not fully understood, it would be prudent to conduct similar pinger spacing trials in other gillnet fisheries and with pingers other than the AQUAmark100 to determine whether the increased effectiveness applies to other gillnet fisheries and other pingers as well. It is very important that such trials are of a magnitude that will allow statistically meaningful conclusions to be drawn and are covered by independent observers, to ensure that the pingers are functioning and are deployed correctly. The results of such trials could lead to more optimal use of pingers, which in turn could lead to a reduction of some of the disadvantages of widespread pinger use.

Acknowledgements. We are grateful to the owner, skipper and crew of the fishing vessel RI 420 'Anette Dahl' for their willingness to participate in this trial, and to the observers who collected the data under sometimes harsh conditions. We are also grateful to 5 anonymous reviewers for suggestions on improvements to this manuscript.

\section{LITERATURE CITED}

Carlström J, Berggren P, Tregenza NJC (2009) Spatial and temporal impact of pingers on porpoises. Can J Fish Aquat Sci 66:72-82

Cox TM, Read AJ, Solow A, Tregenza N (2001) Will harbour porpoises (Phocoena phocoena) habituate to pingers? J Cetacean Res Manag 3:81-86

Culik BM, Koschinski S, Tregenza N, Ellis GM (2001) Reactions of harbor porpoises Phocoena phocoena and herring Clupea harengus to acoustic alarms. Mar Ecol Prog Ser 211:255-260

Gearin PJ, Gosho ME, Laake JL, Cooke L, DeLong RL, Hughes KM (1999) Experimental testing of acoustic alarms (pingers) to reduce bycatch of harbor porpoise, Phocoena phocoena, in Washington State. J Cetacean Res Manag 2:1-9

Gönener S, Bilgin S (2009) The effect of pingers on harbour porpoise, Phocoena phocoena bycatch and fishing effort in the turbot gill net fishery in the Turkish Black Sea coast. Turk J Fish Aquat Sci 9:151-157

Goodson AD, Amundin M, Mayo RH, Newborough D and others (1997) Aversive sounds and sound pressure levels for the harbour porpoise (Phocoena phocoena): an initial field study. Paper CM 1997/Q:17. ICES Annual Science Conference. Theme Session: By-catch of marine mammals, Baltimore, MD. ICES, Copenhagen 
Kraus SD, Read SJ, Solow A, Baldwin K, Spradlin T, Anderson E, Williamson J (1997) Acoustic alarms reduce porpoise mortality. Nature 388:525

Krog C, Larsen F (2007) Anvendelse af pingere i dansk garnfiskeri-overvågning, håndtering og effekt [Use of pingers in Danish gillnet fisheries-monitoring, handling and effect]. Report to the Danish Ministry of Food, Agriculture and Fisheries, October 2007. Available at http://2.naturerhverv.fvm.dk/anvendelse_af_pingere_i_ dansk_garnfiskeri.aspx?ID=32755 (in Danish)

Larsen F (1997) Effekten af akustiske alarmer på bifangst af marsvin i garn [The effect of acoustic alarms on the bycatch of harbour porpoises in gillnets]. Report no. 44-97 (in Danish). Danish Institute of Fisheries Research, Charlottenlund. Available at www.aqua.dtu.dk

Editorial responsibility: Simon Northridge, St. Andrews, UK
Perrin WF, Donovan GP, Barlow J (1994) Gillnets and cetaceans. Rep Int Whal Comm 15(Spec Issue):1-629

Read AJ (2008) The looming crisis: interactions between marine mammals and fisheries. J Mammal 89: 541-548

Read AJ, Drinker P, Northridge S (2006) Bycatch of marine mammals in U.S. and global fisheries. Conserv Biol 20: 163-169

Sokal RR, Rohlf FJ (1995) Biometry: the principles and practice of statistics in biological research, 3rd edn. W.H. Freeman, New York, NY

Trippel EA, Strong MB, Terhune JM, Conway JD (1999) Mitigation of harbour porpoise (Phocoena phocoena) bycatch in the gillnet fishery in the lower Bay of Fundy. Can J Fish Aquat Sci 56:113-123

Submitted: May 31, 2012; Accepted: January 7, 2013

Proofs received from author(s): April 9, 2013 